\title{
«Ustedes son también un sacramento». Reconocimiento y hospitalidad evangélicas
}

Andrea Sánchez Ruiz Welch*

\section{Resumen}

El fenómeno de la migración está teniendo un nuevo rostro. Cada vez más mujeres dejan su hogar buscando un futuro mejor para ellas y para sus familias. En consonancia, esta reflexión desea despertar conciencia sobre la endeble situación de las mujeres migrantes y quiere ser una contribución teológica para el entendimiento de la equidad entre hombres y mujeres en el cruce de migración y género. Como creyentes somos invitados a asumir proféticamente una mentalidad y espiritualidad al servicio de la pastoral de los hermanos y hermanas migrantes. En sintonía con estas búsquedas quisiera ofrecer dos claves evangélicas que podrían acompañarlas: el reconocimiento y la hospitalidad.

\section{Palabras clave}

Migración, género, mujeres, reconocimiento, hospitalidad.

\footnotetext{
Licenciada en teología por la Universidad Católica Argentina. Profesora de Enseñanza Primaria por el Instituto Pedro Poveda, Catequista de niños, adolescentes y adultos por el Centro María Auxiliadora. Se desempeña en la tarea docente en el Profesorado de Ciencias Sagradas Padre Alizalde, en la Escuela Diocesana de Catequesis de San Isidro y otros centros de formación teológica y catequística. Desde el año 2000 participa en grupos de reflexión sobre mujeres y teología y ha presentado en disintos foros la temática mujeres, género y teología. Miembro de la Institución Teresiana y del Programa Teologanda. Contacto: andreasrw@hotmail.com.
} 


\title{
«You are also a sacrament». Recognition and Evangelical Hospitality
}

\begin{abstract}
The migration phenomenon is changing its profile. An increasing number of women are leaving their homes in search of a better future for themselves and their families. Therefore, this reflection tries to raise conscience about the weak position of migrants women, besides giving a theological contribution to the understanding of the equity between men and women, bonding migration and gender. As Christians we are invited to prophetically assume a mentality and spirituality at service of the migrant pastoral. In accordance with this search I would like to bring into consideration two evangelical issues to give support to them: recognition and hospitality.
\end{abstract}

\section{Keywords}

Migration, gender, women, recognition, hospitality.

\section{Introducción}

El fenómeno de la migración está teniendo un nuevo rostro. Cada vez más mujeres dejan su hogar buscando un futuro mejor para ellas y para sus familias. Mujeres itinerantes que anhelan encontrar espacios para su propio desarrollo. Madres que padecen la despedida como el único camino posible para que sus hijos/as puedan crecer dignamente. Abuelas, hermanas, cuñadas, amigas, hijas, que celebran la vida de los y las que quedan, narrando la trama de la cotidianeidad a las/los que se han ido.

En esta ocasión, quisiera invitar a los/las lectores a focalizar la experiencia de la movilidad y emigración en la experiencia de las 
mujeres. Las voces de alerta se encuentran con las estadísticas del continente latinoamericano: de las personas emigrantes del Área Metropolitana Centro-Occidente de Colombia, 54 por ciento son mujeres en el caso de aquellas que viajan a España, y 51 por ciento de las que emigran a Estados Unidos ${ }^{1}$. Ocho de cada 10 mujeres emigrantes que intentan pasar por la frontera norte de México son violadas, sin importar si son niñas, adolescentes o mujeres de edad avanzada. Una parte considerable de ellas son esclavizadas como sirvientas de las bandas criminales o forzadas a prostituirse ${ }^{2}$. El servicio jesuita de refugiados y migrantes denunció el aumento de tráfico de personas de Haití a República Dominicana, siendo las mujeres, especialmente las niñas y las adolescentes las más afectadas, estimándose cerca de dos mil traficadas para la prostitución, el trabajo doméstico y la limosna callejera ${ }^{3}$.

Ser migrante ha dejado huellas permanentes en las personas a lo largo de la historia. En la actualidad se han ido haciendo visibles las marcas del maltrato y la injusticia que pesan sobre quienes emigran. Tanto los hombres como las mujeres son víctimas de violaciones a los derechos humanos en situaciones de movilidad, pero las desigualdades de género han sido puestas en evidencia también en este terreno. De hecho, el cruce de migración y género enfrenta a las mujeres a una doble exclusión: no ser hombres, no ser nativas. La pregunta por la propia identidad se contesta, muchas veces, desde el no ser. Creemos que hay otra respuesta.

Al inaugurar la Conferencia del CELAM, en Medellín (1968), Pablo VI decía en Bogotá a los campesinos: "ustedes son también un sacramento, es decir una imagen sagrada del Señor en el mundo,

1 SEMLAC, "Colombia: feminización de la inmigración en la zona cafetera," www.redsemlac.net/web/ index.php? option=com_content\&view $=$ article\&id=219:colombia-feminizacion-de-la-migracionen-la-zonacafetera\&catid=47: genero\&Itemid $=66$.

2 La Gente, "Ventas de mujeres migrantes, nuevo negocio de narcos en México," www.radiolaprimerisima.com/noticias/inmigrantes/91314.

3 Adital, SJRM denunciaaumento de tráfico de pessoas na fronteira entre Haiti e RD www.adital.com. br /hotsite_trafico/noticia.asp?lang $=$ PT\&cod $=51485$. 
un reflejo que representa y no esconde su rostro humano y divino"4. Estas palabras resuenan también para los migrantes. Jesús, maestro y profeta itinerante, sufrió los embates de la sospecha en razón de su proveniencia, la persecución por abrirse a la diversidad y el acoso por oponerse a las autoridades valladas por el particularismo. Los y las migrantes manifiestan la imagen sagrada de Jesús caminante, recibido y rechazado, aceptado y hostigado. En sus vidas se revela y transparenta la figura del que viene y pone su tienda entre nosotros/as. Si buscamos ser fieles a sus palabras y a su misma vida, no podemos eludir la búsqueda de una justicia largamente esperada, también para las mujeres que migran en condiciones adversas, intentando descubrir en sus vidas esos signos de la presencia del Dios que adviene.

Este artículo desea despertar conciencia sobre la endeble situación de las mujeres migrantes, quiere ser una contribución teológica para el entendimiento de la equidad entre hombres y mujeres en el cruce de migración y género. Brota de la realidad que nos impacta e invita a volver hacia ella para transformarla en la escucha de la Palabra leída, interpretada y explicada en el seno de la Iglesia y en diálogo con los aportes de otras disciplinas.

Para ello los invito a recorrer este camino: en primer lugar, prestaremos atención a la realidad que nos interpela, escuchando las voces de quienes viven situaciones de movilidad, en especial las narraciones de mujeres. En un segundo momento, teniendo en cuenta el aporte de los estudios de género, cruzaremos ambas categorías: migración y género, para analizar sus implicancias. En un tercer momento escucharemos la Palabra de Dios y las enseñanzas de la Iglesia acerca del misterio humano, en la igual dignidad de hombres y mujeres. Finalmente, presentaremos algunas claves orientadoras del quehacer pastoral, para que, a partir de acciones coordinadas, se lleven a cabo proyectos que puedan revertir toda situación contraria a la dignidad de la persona humana, sea del hombre o de la mujer. 
Jesús, que llama bienaventurados a los que trabajan por la paz y a los perseguidos a causa de la justicia, nos invita a empeñarnos en forjar condiciones de vida en la que los valores del reino resplandezcan y puedan hacerse realidad en un mundo sin excluidos. En nuestra encrucijada actual, podemos considerar el actual fenómeno migratorio como un "signo de los tiempos", un desafío a descubrir y valorizar en la construcción de una humanidad renovada y en el anuncio del Evangelio de la paz" ${ }^{5}$.

\section{La realidad nos interpela}

Nadie conoce a esa abuela de dónde es, ni con quien vino, ignorando qué caminos

o qué vientos la han traído... ${ }^{6}$

Soy hija y nieta de inmigrantes. Inmigración no urgida por la peste, el hambre o la falta de trabajo. La partida de mis abuelos fue planificada, atesorada como una promesa para realizar una vida más plena. Aún así, las historias de las patrias lejanas se nos acercaron en la cotidianidad de las comidas, los relatos de la infancia cargados de misterio y añoranza, las cartas releídas de quienes se quedaron, los reencuentros postergados, los sueños compartidos.

Muchos tenemos una experiencia pacífica y agradecida de los que sembraron nuestra biografía con la audacia del que sale y deja atrás su casa, sus padres, sus amigos/as, sus raíces.

5 Pontificio Consejo para la Pastoral de los emigrantes e itinerantes, Erga migrantes caritas Christi (2004): 14. www.vatican.va/roman_curia/pontifical_councils/migrants/documents/rc_pc_migrants_ doc_20040514_erga-migrantes-caritas-christi_sp.html. Ya en 1963, Juan XXIII mencionaba como característica de nuestro tiempo el hecho de que la mujer haya adquirido una conciencia cada día más clara de su propia dignidad humana. "Por ello no tolera que se la trate como una cosa inanimada o un mero instrumento; exige, por el contrario, que, tanto en el ámbito de la vida doméstica como en el de la vida pública, se le reconozcan los derechos y obligaciones propios de la persona humana". Pacem in Terris 41.

6 Enrique Omar Rodríguez, "Lo llamaban Bairoleto", citado en Hugo Chumbita, Ultima frontera. Vairoleto: Vida y leyenda de un bandolero (Buenos Aires: Planeta, 1999). 
Así también nuestros antepasados en la fe. Somos hijos e hijas de un arameo errante, que dejó Ur de los Caldeos buscando suerte en Canaán. Caminamos con Moisés por el desierto después de una larga estadía en Egipto, hasta llegar a la tierra prometida. Salimos con los deportados a Babilonia y cantamos con el salmista su doloroso recuerdo.

Junto a los ríos de Babilonia, estábamos sentados llorando, acordándonos de Sión. En los álamos de la orilla colgábamos nuestras cítaras. Allí mismo nos pidieron cánticos nuestros deportadores, nos pidieron alegría. Canten para nosotros un canto de Sión. ¿Cómo podríamos cantar un canto a Yahveh en un país extranjero? (Sal 135).

El mismo Jesús sufrió el desplazamiento desde niño y su vida, de profeta itinerante, configuró las opciones de sus seguidores/as hasta el día de hoy. El libro de los Hechos nos relata la situación de Aquila y Priscila, quienes tras el decreto del emperador Claudio, que los obligó a salir de Roma, trabaron en Corinto relación con Pablo en su trabajo como tejedores de tiendas y en la tarea misionera compartida.

Somos invitados a ser peregrinos en una tierra que no nos pertenece, aunque en ella echemos raíces. Sin embargo, las huellas de una movilidad forzada dejan la áspera sensación de lo indebido. Los y las migrantes, y su descendencia, se debaten entre dos mundos, no soy de aquí, ni soy de allá... suelen expresar tantas veces con dolor. León Giego, cantautor argentino, le presta su voz al inmigrante, quien, con la melancolía del salmista, se resiste a la risa. Marginado, se resigna al olvido...

\author{
Guarda la risa entre los dientes \\ marcha del sur para el este \\ lleva la sombra que sostiene \\ todo el peso de la gente que más quiere. \\ Lleva incertidumbre \\ y la risa postergada \\ lleva un libro, eso es bastante \\ dice el inmigrante \\ Lleva la cruz del marginado \\ lleva otro idioma \\ lleva su familia, eso es bastante \\ dice el inmigrante
}


Lleva en sus ojos toda la mezcla de la rabia, de la duda y la tristeza tiene que pagar con el olvido lágrima de puerto y de destierro ${ }^{7}$.

Estampas de una experiencia que atraviesa toda la historia, las canciones de inmigrantes, reflejan un destino cargado de recuerdos, tesoros gastados, sentimientos encontrados, dolorosos, madurados.

También los cantos desgarrados de los migrantes clandestinos, los sin papeles, hacen pie entre los jóvenes que viven la violencia de la frontera en su huida.

$$
\begin{gathered}
\text { Podrás imaginarte desde afuera, } \\
\text { ser un mexicano cruzando la frontera, } \\
\text { pensando en tu familia mientras que pasas, } \\
\text { dejando todo lo que conoces atrás. } \\
\text { Si tuvieras tú que esquivar las balas } \\
\text { de unos cuantos gringos rancheros, } \\
\text { las seguirás diciendo good for nothing wetback? } \\
\text { si tuvieras tú que empezar de cero }{ }^{8} \text {. }
\end{gathered}
$$

En estos últimos años, en Latinoamérica y el Caribe, bien sabemos que el desplazamiento de personas a través de las fronteras internacionales ha adoptado complejas modalidades con elevados índices de clandestinidad e informalidad. Un drama que se repite ante la insensibilidad de muchas poblaciones nativas, en el que los jóvenes se arriesgan aún a costa de la propia vida.

En la actualidad, a pesar de estas dificultades, Jorge Martínez Pizarro, profesional del Área de Población y Desarrollo de la División de Población-CELADE, señala que en la agenda regional de América Latina y Caribe se perciben señales de una transformación en la migración internacional: una mayor preocupación por los emigrados y las consecuencias de la emigración, una discusión creciente sobre el papel de las remesas en la economía y la consideración de las mujeres en los flujos contemporáneos que "desafía parte del conocimiento

Molotov, Frijolero. La expresión: good for nothig wetback, significa que los inmigrantes ilegales no son buenos para nada. Wetback textualmente significa "espalda mojada" y alude despectivamente a los migrantes ilegales. 
acumulado e introduce las perspectivas de género y de derechos humanos, en las discusiones sobre migración" ${ }^{\prime}$.

Las estadísticas dan cuenta de la creciente movilidad de las mujeres, que en la actualidad son el $48,8 \%$ del total de migrantes.

\section{Porcentaje de mujeres migrantes en el total de migrantes} internacionales, según regiones. 1960-2000

\begin{tabular}{|l|l|l|l|l|l|}
\hline Regiones & 1960 & 1970 & 1980 & 1990 & 2000 \\
\hline Total Mundo & 46,6 & 47,2 & 47,4 & 47,9 & 48,8 \\
\hline Caribe & 45,3 & 46,1 & 46,5 & 47,7 & 48,9 \\
\hline América Latina & 44,7 & 46,9 & 48,4 & 50,2 & 50,5 \\
\hline
\end{tabular}

Esta participación de las mujeres en los movimientos migratorios deja una impronta peculiar tanto en las economías mundiales como en los mercados laborales. Pero es importante señalar que los fenómenos que se dan en relación a la movilidad de las mujeres no son idénticos a los de los hombres. Si, antiguamente, la motivación de las migraciones femeninas se relacionaban con la conservación del núcleo familiar, siguiendo a sus parejas y llevando consigo a los hijos/as, en la actualidad, aunque en la mayoría de los casos se siga dando este fenómeno, más mujeres están migrando de forma independiente aunque esto conlleve un difícil arreglo dentro del grupo doméstico para que sus hijos/as, si los tienen, sean atendidos por familiares y los maridos "auxiliados" en las tareas domésticas por otros miembros del hogar. Se tiene la certera percepción de que las mujeres reditúan más que los hombres al aportar responsablemen-

9 Jorge Martínez Pizarro, El mapa migratorio de América Latina y el Caribe, las mujeres y el género (Santiago: CEPAL, 2003), 15 www.oas.org/atip/Migration/CEPAL\%20Study\%20on\%20Migration. pdf. Jorge Martínez Pizarro es Geógrafo y demógrafo, investigador del Centro Latinoamericano y Caribeño de Demografía (CELADE)-División de Población de la Comisión Económica para América Latina y el Caribe (CEPAL), en Santiago de Chile. Ha participado en la elaboración de diversos estudios sobre la población y el desarrollo en América Latina y el Caribe, especialmente en el ámbito de la migración.

Ibíd., 20. 
te con recursos al hogar y se convierten, de este modo, en muchos casos, en las principales proveedoras de ingresos en sus hogares ${ }^{11}$.

Sin embargo, la partida y el alejamiento del núcleo familiar dejan una profunda herida en la vida de estas mujeres. El testimonio de Nora, oriunda de Bolivia y residente en Buenos Aires es significativo...

Se sufre, se sufre mucho... Y mucho sufrimiento de amor, y extrañaba a mi marido, extrañaba a mi hija, extrañaba a mis papás, extrañaba a la familia, extrañaba todo, hasta el aire que se respira uno extraña, extraña todo... ${ }^{12}$.

Las mujeres migrantes que dejan en sus terruños a su familia de origen, a sus hijos e hijas y a su pareja, si la tienen, cargan con el peso del mandato cultural que las hace principales responsables de la crianza de la prole y de la "atención" del cónyuge. A la distancia, la experiencia del crecimiento de sus hijos e hijas, se transforma en relato. Los testigos lejanos acercan los acontecimientos significativos como retazos de vida cotidiana.

A esto se suma que muchas veces están expuestas a riesgos mayores que los hombres en cuanto a discriminación, explotación y violencia, ya sea durante sus travesías o en los lugares de destino, en su propio país, como en el cruce de fronteras. La confluencia del género, etnia, nacionalidad e indocumentación puede conducir a las más extremas violaciones de derechos humanos, incluyendo abusos sexuales, deterioro de la salud reproductiva y amenaza a la integridad física.

Así lo relata Edna, brasileña, que vive actualmente en Buenos Aires:

Hace poquito yo estaba en la calle Juan B. Justo esperando el colectivo para buscar al nene; paró un auto y tocaba bocina, pero el tipo no hablaba, él gritaba 'ah, sos brasileña' y cosas, ¿viste?, absurdas totalmente'vení, que cuánto querés, cuánto cobrás...' Estaba con la cabeza afuera del

11 Cf. Ibíd., 5. En adelante sigo al autor en sus conceptos básicos. Cf. Instituto de las Naciones Unidas de Investigación para el Desarrollo Social (UNRISD) versión informática: www.unrisd.org/unrisd/ website/document.nsf/\%28httpPublications\%29/54B9DD585F891F6DC12571630047FFF0?OpenD ocument. Institute of Develoment Satudies 2005, Informe general BRIDGE, versión informática: www.pazysolidaridad.ccoo.es /abrefichero.asp? Idfichero $=24$.

12 Graciela Varela, "Mujeres partidas: análisis discursivo de historias de migración", en Migraciones Internacionales en la Década el 90 en Argentina, ed. Silvia Chejter (Buenos Aires: CECYM, 2005), 144. 
auto. Yo no sabía si gritar o llorar o qué hacía. Y me confundió así como prostituta directamente: 'es brasileña, es prostituta'. Entonces, es algo... Por ahí te miran el pelo y la forma de caminar y por la cara, no sé, y dirán directamente que es brasileña. Es algo que caminamos asustadas. Para mis amigas que son negras es terrible. Directamente como es brasileña, se va a cualquier lado. Es complicado en ese sentido ${ }^{13}$.

$\mathrm{Al}$ riesgo de la violencia de género se suma el engaño cometido por organizaciones dedicadas a la trata de personas con fines de explotación. Las mujeres que han sido víctimas de este tipo de delito se encuentran entre las más vulnerables. Las víctimas de la trata de personas y el tráfico de migrantes son expuestas a todo tipo de vejámenes y maltratos. El trabajo forzado, la explotación sexual, la servidumbre entre trabajadores migratorios y la servidumbre doméstica, el tráfico sexual infantil, etc. son las expresiones de este flagelo que vulnera la esencia misma de la persona: su vida, libertad, integridad y dignidad.

El Instituto de Estudios de Derecho y Ciudadanía realizó el "Curso para Formación de Agentes Multiplicadores en el Enfrentamiento al Tráfico de Personas", los días 23 y 24 de septiembre de 2010 en Fortaleza, Brasil. Uno de los principales problemas alertados durante los dos días de Curso fue la cuestión de la "feminización del tráfico de personas", ya que cerca del $80 \%$ de las víctimas son mujeres, seguidas por adolescentes y niños/as. Muchos especialistas atribuyen este tipo de explotación a la cultura machista todavía dominante y también a la situación de pobreza y miseria que vuelve a las personas más vulnerables a ser explotadas ${ }^{14}$.

El dato es relevante. Nos hace pensar que el impacto de las migraciones forzadas y más el tráfico de personas en la vida de hombres y mujeres, es un fenómeno que no puede ser analizado sin tener en cuenta la cuestión de género. Incluso los movimientos migratorios no son un fenómeno neutro, son experimentados de manera diferencial

14 Adital, Alertas sobre explotación estimulan creación de red contra la trata de personas www.adital. $\mathrm{com} . \mathrm{br} / \mathrm{site} /$ noticia.asp?boletim $=1 \& \mathrm{lang}=\mathrm{ES} \& \operatorname{cod}=51251$. Cf. Informe 2010 sobre la trata de personas www.america.gov/st/democracyhr-spanish/2010/June /20100614112332fjnoeled0. 3156855.html. 
por hombres y mujeres, implicando, en muchos casos, desigualdades injustas hacia las mujeres en razón de su sexo. Las causas de la inequidad son señaladas: el machismo dominante y el empobrecimiento de tantas regiones de nuestro continente, que impacta en las mujeres como una doble marginación ${ }^{15}$. Por tanto, en las páginas que siguen además de recurrir primeramente a los análisis sociales que puedan dar cuenta de las causas de esta inequidad y del entramado de poder que subyace a los vínculos interpersonales, hemos de recordar las enseñanzas de nuestra fe acerca de la igual dignidad de todo el género humano, que darán fundamento a ulteriores reflexiones y desafíos.

El fenómeno migratorio no solo impacta en quienes transitan la experiencia de haber cruzado la frontera. Los «tús» de los y las migrantes, no son solo sus compañeros/as de camino, sus familias, sus amistades, tantas veces añorados. Los «tús» de los y las migrantes pueden ser caras extrañas, que los reciben hostiles, miradas inexpresivas, indiferentes, desafiantes, que exigen su regreso. Pero también pueden ser manos abiertas, brazos extendidos, capaces de crear espacios acogedores. Por qué no pensar que en el encuentro, nos damos y nos recibimos aprendiendo a ser gracias al «tú» que viene. La encarnación nos enseña que el admirable intercambio es factible y que de él todos/as salimos enriquecidos.

\title{
2. La perspectiva de género. Aproximación a la categoría
}

\author{
Cuando vives en la frontera, \\ people walk through you, \\ the wind steals your voice, \\ you're a burra, buey, scapegoat, \\ forerunner of a new race, \\ half and half -both man and woman, neither- \\ a new gender ${ }^{16}$.
}

15 DA 454

16 "Cuando vives en la frontera, la gente te atraviesa, el viento roba tu voz, eres burra, buey, chivo expiatorio, propulsora de una nueva raza, mitad y mitad, tanto mujer como varón, ni uno ni lo otro, un nuevo género". Gloria Anzaldúa, This Bridge Called My Back (Watertown, M.A.: Persephone Press, 1981). 
La poesía mestiza de Anzaldúa deja ver el conflicto de quienes se encuentran en las fronteras. Sobrevivir en las fronteras, significará para muchas mujeres padecer el maltrato, el insulto. Ser pisoteadas, desoídas, ignoradas. Subsistir en la frontera las llevará, no solo a actuar como se supone que una mujer lo haría, sumisa, obediente, con resignación. Si se quiere sobrevivir habrá de ser fuerte, batalladora, agresiva "como un hombre". En las fronteras se configura una nueva identidad. En el cruce de culturas, de lenguajes, de costumbres, de rostros y de piel, se sobrevive sin fronteras...

Anzaldúa nos confronta con la interioridad de quien se encuentra entre dos fuegos, entre dos líneas, con el precario equilibrio de ser o no ser. Sus metáforas aluden al sufrimiento de las mujeres en ese cruce que las degrada por no ser hombres, blancos, descendientes de europeos de Occidente.

Desde esta perspectiva, a new gender, hace referencia a su sospecha sobre la concepción estereotipada de lo femenino y masculino, ya que a lo largo del tiempo y en diversas culturas, han quedado configurados binomios de atribuciones que desfavorecen a las mujeres. Las polaridades: fuerza-debilidad, iniciativa-receptividad, producciónreproducción, actividad-pasividad, mente-cuerpo, razón-intuición, público-privado, sí mismo-otro, sujeto-objeto, civilizado-primitivo, identifican el primer término con lo masculino y el segundo con lo femenino ${ }^{17}$. Así mientras los varones se asociaban con la cultura, equiparaban a las mujeres con la naturaleza, relacionándola con la materia, lo inestable, lo blando y débil. Estas representaciones estuvieron asociadas a lo biológico cuando la ciencia explicaba la inferioridad de las mujeres, la cultura la confirmaba y la enseñanza religiosa la mantenía sin grandes cuestionamientos ${ }^{18}$.

17 Cf. Serene Jones, Feminist Theory and Christian Theology (Minneapolis: Fortress Press, 2000), 25-29

18 Siguiendo las enseñanzas de Aristóteles, Santo Tomás de Aquino afirmaba, de acuerdo a los conocimientos científicos de su época: "Al argumento $1 .^{\circ}$ diremos, que solo con considerar la naturaleza del individuo se ve que la mujer es algo defectuoso y de segundo orden porque la virtud activa del sexo masculino tiende a producir su semejante perfecto del mismo sexo; y la causa de que resulte engendrada hembra es la debilidad de la virtud activa, o alguna indisposición de la materia, o acaso 
Hace años, cuando todavía nos enterábamos del sexo de nuestros hijos en el parto, los genitales daban cuenta de una realidad inmutable. Sin embargo, la idea ahistórica de un sexo biológico que determina infaliblemente nuestra conductas, representaciones, funciones y sentimientos ulteriores, ha sido puesta en tela de juicio. Si a principios del siglo XX se afirmaba "la anatomía es destino"19, a principios del Xxi la cuestión pareciera ser otra: qué destino le damos a nuestra anatomía.

Aunque hoy sea posible modificar alguno de los datos de la biología, en esta reflexión no abordaremos la temática de género para plantear una teoría que propugne la transformación de los sexos, ni para cuestionar la índole biparental de la familia ${ }^{20}$.

El objetivo de este apartado está orientado a considerar la categoría de género ${ }^{21}$ como una herramienta válida para señalar si el origen de las injusticias sociales debidas al hecho de ser hombre o mujer tienen su raíz en la biología humana, o en la manera en que esta biología es interpretada por la cultura. Si las desigualdades entre hombres y mujeres no tienen su raíz en la biología, estaríamos en condiciones de proponer caminos evangélicos capaces de reconstruir vínculos entre ambos, que no sean opresivos y discriminatorios sino de justicia y equidad.

alguna transformación procedente de fuera, como de los vientos australes, que son húmedos". Santo Tomás de Aquino, S. Th. I, q. 92 a. 1 ad 1. Posteriormente la pedagogía de Rousseau, por citar un ejemplo, confirma esta concepción: “Toda educación de las mujeres debe hacerse en función de los hombres. Complacer y ser útiles para ellos, hacerse amar y honrar, educar a los pequeños, cuidar a los mayores, aconsejarlos, consolarlos, hacerles agradable y dulce la vida: éstos son los deberes de todas las mujeres en todas las edades de la vida y ésto debe enseñárseles desde la infancia". Recopilación de: Giulia Di Nicola, Reciprocidad hombre-mujer (Madrid: Narcea, 1991), 105-119.

19 La expresión: "La anatomía es el destino" aparece por primera vez en 1912 en el artículo de Freud "Sobre la degradación general de la vida erótica" y la segunda vez en 1924 en el escrito "El hundimiento del Complejo de Edipo".

20 Carta a los Obispos de la Iglesia Católica sobre la colaboración del hombre y la mujer en la Iglesia y el mundo, 2. www.vatican.va/roman_curia/congregations/cfaith/documents/rc_con_cfaith_ doc_20040731_collaboration_sp.html

21 No me refiero a la ideología como la presenta Aparecida (DA 40). Es necesario aclarar que la distinción entre sexo-género no se plantea en este caso como oposición naturaleza-cultura. De lo contrario estaríamos reproduciendo el dualismo que caracterizó durante siglos algunos sectores de la cultura occidental. Cf. Silvia Tubert, "La crisis del concepto de género" y Genevieve Fraisse, "El concepto filosófico de género" en Del sexo al género. Los equívocos de un concepto, ed. Silvia Tubert (Madrid: Cátedra 2003), 7-37 y 39-46, respectivamente. 
De lo contrario tendríamos que conformarnos con atribuir a nuestra condición sexual la injusta jerarquización de los géneros de forma ineludible. Jerarquización contraria a la praxis y las enseñanzas de Jesús transmitidas en los evangelios.

En la actualidad, aun cuando aceptemos la importancia fundamental del sustrato biológico, sabemos que no es lo único que nos hace ser quienes somos. Los vínculos primarios, las relaciones sociales, la inserción en determinada cultura y contexto geográfico e histórico, las convenciones y costumbres, la simbólica construida a través del tiempo, la familia y las instituciones que nos han educado, configuran nuestra subjetividad. Por tanto, a la hora de pensar cómo se conforma la identidad masculina y femenina, tenemos que atender no solo a nuestra biología, sino a los significados que se le atribuyen culturalmente a cada sexo.

Desde que Robert Stoller, psicoanalista y psiquiatra estadounidense, distinguió el concepto de "género", como construcción cultural, de "sexo", inscrito en nuestra corporalidad", se ha recorrido un largo camino en los estudios de género, en el que encontramos discrepancias y acuerdos entre los teóricos y teóricas. Sin entrar en ellos, trataremos de responder a la pregunta inicial de Marta Lamas, antropóloga mexicana, en relación a la cuestión que estudiamos:

Ahora bien, respecto a las personas, zqué diferencia hay entre el concepto de sexo y el de género?, ¿qué hace femenina a una hembra o masculino a un macho?, ¿̇su anatomía, su sexo?, ¿qué es lo femenino y qué lo masculino?, ¿por qué lo que se considera femenino en una cultura en otra es visto como masculino? ${ }^{23}$.

La pregunta por lo femenino y masculino está asociada a la interpretación histórica del sexo biológico, del cual no se independiza, sino que es su fundamento. Somos esta mujer y este hombre, pero el entorno representa y simboliza, transmite y educa el modo en que

22 R. Stoller y G. Herdt, "El desarrollo de la masculinidad: una contribución transcultural", Revista de la Asociación Escuela Argentina de Psicoterapia para Graduados (1992): 18.

23 Marta Lamas, "La antropología feminista y la categoría de género", en Nueva antropología. Estudios sobre la mujer: problemas teóricos, ed. Ludka de Gortari (Iztapalapa: CONACYTI/UAM, 1986), 30. 
se vive la condición sexual difiriendo entre culturas y épocas. Por tanto, desde la infancia aprendemos lo que para nuestros ambientes es "lo femenino" y "lo masculino" y tratamos de hacerlo propio. De hecho, lo que hace femenina a una mujer en nuestras sociedades urbanas no es lo mismo que 150 años atrás. Tampoco la forma de vivir la masculinidad aquí, hoy, entre los jóvenes de Suecia o Arabia Saudita. Juan Pablo II ya advertía que "somos herederos de una historia de enormes condicionamientos que han hecho difícil el camino de la mujer"24. Pero la cuestión de género no solo hace referencia a lo femenino, aunque en la historia haya sido más perjudicada. Los condicionamientos son compartidos por hombres y mujeres. También los hombres han percibido, en este último tiempo, que las atribuciones de género que configuran la masculinidad hegemónica o tradicional no son garantía de una existencia plena.

En este sentido, los aportes de los estudios de género ofrecen un marco teórico y una categoría de análisis que permite explicar las diferencias entre los sexos, no solo desde lo biológico sino también desde el terreno simbólico, delimitando así, con mayor claridad y precisión, cómo la diferencia ha ido adquiriendo una condición de desigualdad, dando razón de las persistentes asociaciones de la masculinidad con el poder y el valor superior asignado a los hombres sobre las mujeres. Desde esta perspectiva, los significados atribuidos a lo femenino y masculino se modifican en el decurso de la historia y en los diversos contextos sociales. Por tanto, es posible esperar que las atribuciones y representaciones jerarquizadas den lugar a relaciones simétricas, de reciprocidad y justicia.

Aun cuando en la actualidad se está caminando hacia una progresiva disminución de la oposición entre los géneros, sabemos que las asignaciones colectivas han ido construyendo subjetividades sexuadas diferenciadas. Históricamente, estas asignaciones esta-

24 Juan Pablo II, Carta a las mujeres, 3. www.vatican.va/holy_father/john_paul_ii/letters/documents/ hf_jp-ii_let_29061995_women_sp.html 
ban establecidas por la biología y se vinculaban a los procesos de subjetivación, realizados ad intra de la comunidad familiar y a los modelos de la educación formal. Hoy se considera también que la producción y reproducción de la identidad de género está íntimamente vinculada a los sistemas simbólicos, a las formas en que las sociedades representan el género y hacen uso de este para enunciar las normas, las relaciones sociales o para construir el significado de la experiencia. Por consiguiente, no es posible aislar la categoría género de otros condicionantes de la subjetividad humana como la raza, la religión, la clase social, la etnia, etc. Tampoco habrá que disociarlo de lo que Scott denomina "forma primaria de relaciones significantes de poder"25. Con ello se refiere a que las relaciones de género entrañan una lógica de poder y dominación, que implica o ha implicado, el control diferencial, por parte de hombres y mujeres, sobre los recursos materiales y simbólicos, o el acceso a los mismos. En este sentido, el análisis de género permite decodificar significados y comprender las complejas conexiones entre varias formas de interacción humanas ${ }^{26}$.

En síntesis, la perspectiva de "género" permite hacer visible, en las situaciones concretas de la vida cotidiana y de los vínculos sociales, la desigualdad en las relaciones entre hombres y mujeres. Entrar a la realidad desde el enfoque de género hace posible desocultar la trama del poder en los vínculos interpersonales y en los aspectos culturales y simbólicos de la identidad construida a partir del sexo biológico de hombres y mujeres.

En sus usos más descriptivos, el género es utilizado para estudiar asuntos donde las relaciones entre los sexos son más directamente

25 Cf. Joan Scott, "El género: una categoría útil para el análisis histórico", en Sexualidad, género y roles sexuales, ed. M. Navarro y C.R. Stimpson (México: Fondo de Cultura Económica, 1999), 37-75.

26 Los comportamientos aprendidos configuran la identidad de género y establecen los roles de género, así como las relaciones de género, que pueden ser diferentes dependiendo del tiempo y la sociedad. Los factores como la edad, la raza, la religión, la clase y la educación influyen en los roles de género. A su vez, el género y los roles de género son factores principales en la definición y la determinación del acceso de las mujeres y de los hombres al poder y a los recursos. 
evidentes. Entre ellos, las relaciones familiares, la violencia doméstica, la salud, la educación. También en relación con la política y la económica, las relaciones institucionales, las migraciones, las ciencias, las artes, los deportes, las iglesias, etc.

Es importante, por consiguiente, entender el modo en que el género opera como elemento estructurante de las relaciones sociales en su conjunto y como forma primaria del significado del poder, para interpretar las dinámicas sociales en la actualidad. Como categoría de investigación, permite comprender las experiencias concretas de hombres y mujeres en los diversos contextos históricos. Por tanto, como herramienta de análisis y perspectiva de estudio, ofrece, junto a otros factores, la posibilidad de visibilizar relaciones de inequidad en los vínculos interpersonales y emprender la marcha para un cambio, contribuyendo al establecimiento de sociedades cada vez más democráticas, más justas e igualitarias.

\section{Género y migración}

Hoy necesitamos resignificar la perspectiva de género, incorporándola al camino evangélico de la justicia y de la equidad ${ }^{27}$.

Con la mirada puesta en el Evangelio, buscando la justicia y la equidad en las relaciones interpersonales, en los contextos sociales y culturales de nuestro tiempo, se presenta un desafío que no puede ser eludido: estudiar los vínculos entre género y migración.

Las últimas investigaciones han puesto en evidencia que las mujeres no emigran solamente como dependientes de los proyectos masculinos, sino que se marchan para insertarse en el mercado laboral y muchas veces encabezan las estrategias de supervivencia familiares, por lo que existe un particular interés en orientar los

27 Mons. Fernando Bargalló, Alocución apertura II Foro Regional de Género, 8 de octubre de 2010 www.caritaslac.org/noticia.aspx?id=670. Mons. Bargalló es Presidente de Pastoral Social-Caritas de la Región América Latina y el Caribe. 
estudios de género para recuperar el papel de las mujeres en las migraciones ${ }^{28}$. Con relación a las causas de las migraciones se ha puesto en evidencia que si los varones emigran principalmente por motivos económicos, en el caso de las mujeres también pesan los factores relacionados con la dominación patriarcal, como la violencia de género ${ }^{29}$. También se percibe que muchas mujeres se ven forzadas a emigrar para sustentar a sus familias, cuando toman conocimiento de que en otras regiones los puestos de trabajo se feminizan. Tal es el caso de la "extranjerización" ${ }^{30}$ del servicio doméstico, como veremos más adelante.

Los estudios de género también permiten evidenciar cómo es interpretada la presencia de mujeres migrantes en el imaginario común de nuestras culturas y cuál es la construcción de significados en torno a ellas.

En relación con esta temática los trabajos de Carmen Gregorio Gil hacen un aporte valioso desde la antropología social, advirtiendo que la construcción de los discursos sobre las mujeres migrantes se inscriben en un planteo más amplio: la amenaza que representa para las naciones europeas la avalancha de inmigrantes que pone en peligro el bienestar de los ciudadanos y ciudadanas nativos ${ }^{31}$. Construido así el discurso, las mujeres inmigrantes son visibilizadas como un colectivo uniforme, asociado a la prostitución, a las prácticas culturales de sus lugares de origen, a su elevada natalidad y se

28 Pilar Goñalons, Ramón Flecha, Iñaki Santacruz y Carlos Gómez, “Las aportaciones y los retos de la perspectiva transnacional: Una lectura de género", Congreso Nuevos Retos del Transnacionalismo en el Estudio de las Migraciones (Barcelona: febrero 2008), 12-14. http://docsgedime.wordpress.com.

Ángeles Escrivá ha investigado la problemática de las mujeres peruanas que se han insertado en el servicio doméstico en la ciudad de Barcelona. En sus investigaciones señala el hecho de que la posición y el rol de las mujeres dentro de la familia es un determinante crítico de la emigración femenina. "Es dentro de la familia donde mejor se manifiesta la subordinación de las mujeres a la autoridad masculina. Esta dinámica intrafamiliar, jerárquica en términos de sexo y edad, que condiciona la emigración femenina, se refleja en la historia de muchas emigrantes, entre ellas Judy Edith, una peruana que fue «obligada», literalmente, por su hermano mayor a emigrar a España dejando a su único hijo a cargo de la familia." Ángeles Escrivá, "¿Empleadas de por vida? Peruanas en el servicio doméstico de Barcelona", Papers 60 (2000): 327-342, 331.

30 Pilar Goñalons, Ramón Flecha, Iñaki Santacruz y Carlos Gómez, op. cit., 15.

31 Cf. Carmen Gregorio Gil, "Mujeres inmigrantes: colonizando sus cuerpos mediante fronteras procreativas, étnico culturales, sexuales y reproductivas", Viento Sur 104 (2009): 42-54. 
las considera necesarias para facilitar la integración familiar en el país de destino. Se produce así este fenómeno: son excluidas de la ciudadanía por ser extranjeras e incluidas en su función de madres y esposas como una estrategia de adaptación cultural y social de las familias a los nuevos contextos. Esta situación se construye a través de discursos que enfatizan las diferencias de las mujeres migrantes (otras) respecto de la ciudadanía (nosotras), erigiendo fronteras simbólicas que las marginan. Entre ellas Gregorio Gil señala las fronteras procreativas, étnicas, culturales, sexuales y reproductivas.

Con las fronteras procreativas alude a las sospechas que genera la "desbordada natalidad"32 de las mujeres migrantes, que desde perspectivas xenófobas pone en peligro los sistemas de salud (desconociendo las propias prácticas sanitarias de las inmigrantes) e incluso las identidades nacionales. Otra frontera que separa a las migrantes de las mujeres autóctonas es la construcción de una imagen "bárbara" o "salvaje" de sus culturas de origen, estigmatizando ciertas prácticas de las cuales hay que liberarlas con discursos salvadores, ignorando tanto las luchas que las mismas mujeres realizan contra esas mismas prácticas en sus países de origen, así como las múltiples formas de dominación que se ejerce sobre estas mujeres en las culturas receptoras.

En relación con las fronteras sexuales, Gregorio Gil señala que la deliberada asociación entre inmigración, prostitución y trata de personas, enmascara las trabas que impone el mercado y la comunidad al ingreso laboral de las mujeres inmigrantes. Finalmente, destaca el rol que se les asigna a las madres dentro del propio ámbito familiar como transmisoras de su cultura y de la lengua de origen, para la contención social de los niños/as y jóvenes de segunda generación que, inmersos en una doble cultura, son considerados en "riesgo social". ${ }^{33}$ Así se genera una nueva frontera que considera a las mu- 
jeres migrantes, no como actoras sociales en el ámbito público, sino como "reproductoras sociales de sus grupos domésticos y mediadoras entre éstos y la sociedad de acogida"34.

Saskia Sassen, en sus investigaciones sobre perspectiva de género en la economía global, presenta como prometedores los estudios que analizan el modo en que la migración internacional altera los patrones de género y cómo la formación de hogares transnacionales puede empoderar a las mujeres ${ }^{35}$. Para la autora, suponer que se ha entendido la cuestión de género por haber denunciado la discriminación en el pago a las mujeres y la alta incidencia de las ocupaciones diferenciadas por géneros, disminuye la importancia teórica, empírica y política de la cuestión. Señala que, en relación a las mujeres, hay que distinguir dos dinámicas diferenciadas. En primer lugar, aquellas que las configura como una clase de trabajadoras invisibles y desapoderadas. En segundo lugar, las consecuencias que genera el acceso a un salario.

Deteniéndonos en el primer aspecto, entre las cuestiones que reclaman mayores estudios y acciones consecuentes, se señala la necesidad de atender a la noción "clase de servicio", que apunta a la vasta oferta de trabajadores/as de bajos ingresos, generalmente inmigrantes.

Estos servicios, también llamados de «proximidad» o de «vida diaria», son escasamente valorados por la sociedad, que los considera propios de la condición femenina, trabajos que el mercado no reconoce como tales, con un fuerte imaginario servil ${ }^{36}$. Asociados a la baja

\footnotetext{
$34 \quad$ Ibíd., 51

35 Cf. Saskia Sassen, Los espectros de la globalización (Buenos Aires: Fondo de Cultura Económica, 2003), 115. Sassen es socióloga y filósofa, especialista en estrategias urbanas. Sigo a la autora en el capítulo referido al análisis feminista de la economía global, 111-137.

36 Cf. Sonia Parella Rubio, Mujer, inmigrante y trabajadora: la triple discriminación (Barcelona: Anthropos, 2003), 12. Carmen Gregorio Gil señala que a fines de los 90 en España el sector servicios es ocupado en forma mayoritaria por mujeres, un $94,3 \%$ de los permisos otorgados a las mujeres inmigrantes entran dentro de este sector. Carmen Gregorio Gil, Migración femenina: su impacto en las relaciones de género (Madrid: Narcea, 1998), 45. También Escrivá señala el hecho de que "las mujeres migrantes se inserten abrumadoramente en segmentos laborales etnificados y sexualmente diferenciados". Ángeles Escrivá, op. Cit., 328.
} 
estima social, el desprestigio y la descualificación, son rechazados por las mujeres jóvenes autóctonas. A la vez, la incompatibilidad entre sus propios trabajos remunerados y las ocupaciones en la esfera doméstica-reproductiva, ha provocado una mayor demanda de estos servicios. Para llenar este vacío laboral se contratan empleadas de países periféricos, generando "cadenas globales de cuidados"37 que funcionan con el objetivo de sostener cotidianamente la vida, transfiriendo trabajos de cuidados de unos a otros, incluso a nivel transnacional.

De este modo la posición laboral de la mujer inmigrante en las sociedades receptoras y su concentración en los denominados «servicios de proximidad»

revela la etnoestratificación del mercado del trabajo en el sentido de mostrar la segregación ocupacional de la mujer inmigrante como resultado de la confluencia de un triple proceso de discriminación (clase, género, etnia) y el consiguiente fortalecimiento de una rígida división social dentro del propio colectivo femenino, entre mujeres que son «servidas" y mujeres que ejercen como «servidoras $»^{38}$.

Sassen también alude a este fenómeno. Observa cómo "la mujer inmigrante sirviendo a la mujer profesional blanca de clase media, reemplaza la tradicional imagen de la mujer negra sirviendo a un patrón blanco"39. Aunque las situaciones cambien, los imaginarios permanecen. El trabajo remunerado en casas de familia puede pres-

Arlie Hochschild ha introducido el concepto de cadenas globales de cuidados para explicar las nuevas dinámicas del servicio doméstico global. Una mujer de clase media contrata una empleada para cuidar un enfermo, a su vez la empleada deja a sus hijos al cuidado de una tercera que dejó en su país de origen a su familia al cuidado de las abuelas. En muchos casos en las cadenas alternan nativas y migrantes. Cf. Amaia Orosco, Cadenas globales de cuidado (Santo Domingo: INSTRAW, 2007), 4. Gregorio Gil también se ocupa de la maternidad a distancia poniendo en el tapete "la necesidad de tomar conciencia de la explotación que inflingen algunas mujeres a sus hermanas". Carmen Gregorio Gil, "Debates feministas en el análisis de la inmigración no comunitaria en el estado español. Reflexiones desde la etnografía y la antropología social", Relaciones Internacionales 14 (2010): 93115,101. Disponible en: http://relacionesinternacionales.info/ojs/index.php?journal=Relaciones_Int ernacionales \&page = article\&op =view\&path $\% 5 \mathrm{~B} \% 5 \mathrm{D}=217 \&$ path $\% 5 \mathrm{~B} \% 5 \mathrm{D}=196$.

38 Sonia Parella Rubio, op. cit., 17. Gregorio Gil señala que la "múltiple discriminación" de que son víctimas las mujeres no tiene que llevarnos a pensar que no pueden ser agentes de su propio cambio. Carmen Gregorio Gil, “Debates feministas en el análisis de la inmigración no comunitaria en el estado español. Reflexiones desde la etnografía y la antropología social", op. cit., 103-104.

Saskia Sassen, op. cit., 123. 
tarse al abuso por parte de los empleadores/as mientras no atiendan al horario establecido, los descansos obligados, el trato digno, la paga justa. Con todo, muchas mujeres que deciden emigrar buscando además del bienestar para sus familias, el desarrollo y la autonomía personales, encuentran una posibilidad inicial de ingresar al mercado laboral en el servicio doméstico. Esta circunstancia nos lleva a considerar la segunda dinámica estudiada por Sassen, quien advierte que, aún siendo bajos, el acceso a salarios es un factor determinante, tanto como la feminización de la oferta laboral y las mayores oportunidades de negocios que se generan. Las trabajadoras proveen y administran sus recursos con cierta independencia, invirtiendo en el bienestar colectivo y sosteniendo en el tiempo el envío de remesas. Esto incide a su vez en las relaciones de género: las mujeres adquieren mayor autonomía personal mientras los hombres ven modificados (a veces disminuidos) sus ámbitos de acción y decisión. Cambian los vínculos intrafamiliares porque comienzan a ejercer mayor control sobre los acuerdos domésticos, involucrando a los hombres en las tareas cotidianas y se encargan de administrar el presupuesto. En algunos casos, este empoderamiento provoca diferencias a la hora de tomar decisiones respecto al regreso al país de origen. Las mujeres quieren asentarse, los hombres volverse. La dinámica que hace visible este deseo fue observada al considerar que las mujeres gastaban gran parte de su salario en bienes de consumo durables y los hombres ahorraban para el regreso.

Sassen señala también que, unido a estos cambios en el hogar, se produce una mayor participación en la esfera pública, principalmente en dos escenarios: las instituciones de asistencia pública y privada y la comunidad étnica de inmigrantes.

Estas observaciones, de índole urbana, no deben opacar las dolorosas situaciones en las que migrantes son sometidas a vejaciones y maltratos o se convierten, como en el caso de las zonas semiáridas del Nordeste de Brasil, en "viudas de la sequía". Las migraciones de hombres a gran escala deja a las mujeres a cargo del hogar $y$, en 
muchos casos, sus esposos nunca envían las remesas prometidas ni regresan. Con todo el desasosiego y vulnerabilidad que esta situación genera en la vida cotidiana de las mujeres y sus familias, sin embargo, muchas mujeres se han convertido en líderes activistas consiguiendo participar en ámbitos mayoritariamente masculinos, gestionando actividades comunitarias, generando redes, favoreciendo acciones para evitar la desertificación ${ }^{40}$.

En muchos países latinoamericanos los índices de trata de personas han ido en aumento. En Argentina han desaparecido en 2010, 627 mujeres y niñas. Madres de jóvenes desaparecidas se han organizado para desenmascarar las conexiones locales y sus vínculos internacionales, que en muchos casos actúan con la complicidad de los poderes públicos, gestionando redes de madres con hijos e hijas desaparecidos y estableciendo centros de acogida para mujeres maltratadas ${ }^{41}$.

Son 200000 los/las inmigrantes que se montan cada año a los "trenes de la muerte" para cruzar México y llegar a EE.UU. Los narcotraficantes los asaltan o secuestran. Las mujeres son también violadas. El año pasado, de acuerdo a la Comisión de Derechos Humanos de México, fueron secuestrados oficialmente 9758 migrantes centroamericanos. Ante esta situación desesperada, un grupo de quince mujeres hace comida para ayudar a los miles de inmigrantes centroamericanos que pasan por el pueblo de Guadalupe-La Patrona. Las Patronas, viven a la vera de las vías y ven transitar dos o tres veces por día a los muchachos y chicas colgados de los trenes de carga, que piden agua y comida para no morir en el intento y les arrojaran una bolsa con la cena y el agua que necesita para sobrevivir hasta la próxima parada. Reciben donaciones de decenas de pequeños em-

40 Cf. UNEP, "La mujer y la desertificación", www.unep.org/PDF/Women/Spanish/ChapterFour.pdf.

41 Ahora es nuestra ciudad, "Fabiana Tuñez: en el último año han desaparecido 627 mujeres y niñas", http://ahoraesnuestralaciudad2009.blogspot.com/2010/03/fabiana-tunez-en-el-ultimo-ano-han. html. 
presarios. No tienen ningún subsidio o sueldo personal. La decisión del emprendimiento está sellada por su fe católica ${ }^{42}$.

El cruce de migración y género nos ha permitido analizar la situación de las mujeres que sufren las consecuencias de la migración forzada. Si bien históricamente, en el mundo, las migraciones han sido de familias o encabezadas por los hombres, quienes abrían el camino en el nuevo territorio para luego reunificar a la familia, esta tendencia se ha roto. La feminización de la migración estaría indicando un cambio en los roles de género, en la reagrupación familiar y en la administración de remesas. La posibilidad que tienen las mujeres de entrar más fácilmente en el mercado laboral en el servicio doméstico provoca, en muchos casos, que una familia envíe primero a una mujer para abrir la puerta a ulteriores migraciones con la confianza de que, aún con montos más bajos, las remesas serán constantes. ${ }^{43}$ Las implicancias de este fenómeno en la vida de las mujeres que llegan a los países de destino generan situaciones ambiguas. Por un lado, se enfrentan a un medio hostil que las segrega y a la vez las necesita. Por otro, para muchas mujeres, las nuevas condiciones laborales, aunque precarias, generan un proceso de empoderamiento: se encuentran con la posibilidad de desarrollar su propio proyecto de vida y de liberarse del control social, ya que se genera un clima de confianza ante la percepción de que las mujeres son mejores administradoras del dinero familiar.

A la vez se verifica una creciente participación en la arena pública, promoviendo espacios solidarios y redes de acción que las vincula cercana y eficazmente a la situación de extrema necesidad que padecen muchos/as de los que migran obligadamente. Con el

42 Gustavo Sierra, "Los jinetes de La Bestia", Clarín, 3 de abril de 2011, Sección Zona.

43 De hecho, se ha constatado que los hombres envían más altas remesas, pero lo hacen durante un tiempo y luego suspenden el envío. Cf. Linda Eriksson, "Género y remesas: migración colombiana del AMCO hacia España", OIM y el Instituto Internacional de Investigaciones y Capacitación de las Naciones Unidas para la Promoción de la Mujer, 2005. Disponible en: http://tukuymigra.com/ images/normativa/COL_EST_OIM-DANE_4.pdf. 
descubrimiento y valoración de las propias potencialidades aparece en ellas el compromiso social.

No solo la sociedad civil, también la Iglesia ha de sentirse interpelada a responder activamente a las demandas que surjan al asumir la perspectiva de género en el análisis de las causas, los trayectos y las consecuencias de la migración para las personas y las comunidades. Como afirmaba Juan Pablo II:

\begin{abstract}
Así pues, el reciente fenómeno de una mayor presencia de la mujer en la emigración requiere un cambio de perspectiva en el enfoque de las respectivas políticas, al tiempo que manifiesta la urgencia de garantizar también a las mujeres la igualdad de trato, ya sea con respecto a la retribución, ya con respecto a las condiciones de trabajo y de seguridad. De ese modo, será más fácil prevenir el riesgo de que la discriminación de los emigrantes en general tienda a encarnizarse especialmente con la mujer ${ }^{44}$.
\end{abstract}

Este cambio de perspectiva también habrá de dirigirse hacia el interior de las comunidades eclesiales, en la efectiva afirmación de la igual dignidad de hombres y mujeres, en una creciente toma de conciencia acerca de la realidad de la movilidad humana que lleve a los/las creyentes al reconocimiento y valoración del inmigrante tanto en el ámbito público como doméstico, en la denuncia profética de los atropellos que sufren frecuentemente los que emigran, en especial las mujeres. De este modo se podrá promover una participación cada vez más plena de las mujeres en la vida familiar, social y eclesial, generando estructuras que favorezcan la inclusión y la equidad $^{45}$.

En la escucha de la Palabra, las comunidades vuelven una y otra vez a sentirse interpeladas para reconocer y recibir al otro/la otra como un hermano, una hermana: alguien que nos pertenece y de quien habremos de dar cuenta. 


\section{Para Dios soy como tú, formado también de arcilla... Job 33,3}

La antropología cristiana resalta la igual dignidad entre varón y mujer en razón de ser creados a imagen y semejanza de Dios.

El misterio de la Trinidad nos invita a vivir una comunidad de iguales en la diferencia ${ }^{46}$.

Es indudable que las diferencias sexuales nos configuran como hombres y mujeres haciendo posible la rica experiencia del amor, la generación de la vida, la convivencia y el intercambio recíproco. Sin embargo, tantas veces estas diferencias, en lugar de enriquecer los vínculos interpersonales, han generado y generan injusticias provocadas por razones de sexo. Juan Pablo II reconocía la fuerza de las sedimentaciones culturales en este proceso que, a lo largo de los siglos, han plasmado mentalidades e instituciones. Por desgracia, afirma, "somos herederos de una historia de enormes condicionamientos que han hecho difícil el camino de la mujer, despreciada en su dignidad, olvidada en sus prerrogativas, marginada frecuentemente e incluso reducida a esclavitud". ${ }^{47}$ Evidentemente, la herencia cultural deja marcas que han plasmado las mentalidades e instituciones a lo largo de la historia. De esto nos ocupábamos al señalar la pertinencia de incorporar la categoría de género al estudio del fenómeno migratorio.

Con todo, nuestra fe nos enseña la verdad más radical sobre el ser humano, que tiene su origen en Dios. Las imágenes bíblicas acerca de la génesis de la humanidad, conservadas y reinterpretadas por el pueblo, dan cuenta de que la afirmación que enhebra las tradiciones judeocristianas sobre el misterio humano es que fuimos creados-creadas a imagen y semejanza de $\operatorname{Dios}^{48}$.

\footnotetext{
$46 \quad$ Ibíd., 452.

47 Juan Pablo II, Carta a las mujeres, op. cit. 3.

48 La antropología cristiana, recuerda Juan Pablo II, "encuentra la base inmutable de toda afirmación sobre el ser humano, hombre y mujer, en la verdad revelada en el Génesis: «creó pues, Dios al ser humano, a imagen suya lo creó, a imagen de Dios lo creó» ( Gen 1,27) y continúa: ambos son seres
} 
La expresión "imagen y semejanza" ha sido explicada de diversas maneras a lo largo de la historia en la reflexión teológica.

Atendiendo al original hebreo imagen (tselem) denota la representación plástica de una estatua capaz de identificarse con aquel a quien representa. Semejanza (demut), alude a los planos, al boceto del arquitecto. En el Génesis se concreta en el señorío humano sobre la tierra y sus criaturas, gobernando, haciendo uso y cuidando del mundo como representantes de Dios. La patrística interpreta la imago de un modo más esencial, como la afinidad de la raza humana y la realidad divina, una relación interrumpida por la separación provocada por el pecado. Los teólogos medievales buscaron el contenido de la imagen en el alma humana con su don espiritual de racionalidad. Interpretaciones más recientes han identificado la imagen de Dios con la creatividad humana, o con la comunidad humana, o con la semejanza de los seres humanos con Dios en toda su persona, incluyendo la forma corporal. Entonces podemos decir que el ser humano dice relación a Dios, es el tú del creador y su representante, depende de él para existir, en él está su origen y no solo en el cosmos y sus habitantes, aunque esté emparentado con ellos. Allí donde está el ser humano, Dios se refleja y se hace presente y esto constituye su dignidad más profunda: nadie puede, entonces, atentar contra otro ser humano, nadie puede borrar la imagen viva de Dios. Nos vincula un imperativo moral irrenunciable: reconocer que "para Dios soy como tú, formado también de arcilla" y promoverlo mediante una praxis transformadora. Por tanto, todos los miembros de la especie se ven favorecidos igualmente por la identidad teológica de imago Dei. Somos teomorfos, teomorfa ${ }^{49}$.

La radicalidad de esta afirmación no deja lugar a dudas. Hombres y mujeres somos iguales en dignidad. Jesús mostró con sus opciones

humanos en el mismo grado, y esta imagen y semejanza con Dios personal es esencial al ser humano y los configura a ambos igualmente personas". Mulieris Dignitatem, 6.

49 Cf. José L. Sicre, El Pentateuco. Introducción y textos selectos (Buenos Aires: San Benito, 2004); Elizabeth Johnson, La que es (Barcelona: Herder, 2002); María Clara Bingemer, Um rostro para Deus? (Sao Paulo: Paulus, 2005). 
que era heredero de estas tradiciones (Cf. Mc 10,1-12) y como revelador del Padre confirmó con sus acciones las palabras del Génesis, generando una praxis inclusiva que sorprendía en un contexto hostil a las mujeres, los pobres, los enfermos, los impuros.

La segregación y las jerarquizaciones entre clases, grupos religiosos y sexos, era moneda corriente en el mundo grecorromano y judío del siglo I. Los miembros de la elite no se relacionaban con los que no eran de su mismo rango, las mujeres permanecían separadas de los asuntos masculinos y los límites que imponía el trato con los paganos en el mundo judío, solían ser difíciles de franquear. No respetar estas reglas del honor en la convivencia ponía en peligro la pertenencia al círculo, la fortuna y el honor de la familia. Quienes compartieron la vida con Jesús, bien sabían que su mensaje y su testimonio no coincidían con los cánones de la época y que incluso, en varias ocasiones, había manifestado públicamente su oposición a tales costumbres. Su actitud provocativa entraría en conflicto con un sistema social y religioso preciso, difícilmente integrador, no solo en el judaísmo sino también en la sociedad grecorromana, ya que sus costumbres se verían interpeladas con la extensión del cristianismo. De allí que Pablo, recogiendo estas enseñanzas, exhorta a las comunidades en la carta a los Gálatas, a vivir en Cristo sin divisiones excluyentes: "No hay judío ni griego; no hay esclavo ni libre; no hay hombre ni mujer; porque todos son uno en Cristo Jesús" (Gal $3,28)$. Los evangelios dan testimonio de esta verdad, al narrar los encuentros personales y públicos de Jesús con gentes consideradas marginales en el ambiente.

Siguiendo las enseñanzas del Maestro, transmitidas por la Iglesia, en la actualidad el magisterio eclesiástico vuelve a anunciar, una y otra vez, la verdad sobre la persona humana ${ }^{50}$. Su palabra sexos hacia cierto dualismo jerárquico que, imperante en el contexto histórico y social, al pasar al discurso eclesiástico, se convirtió en muchos casos en norma de vida y costumbres, en la familia y en la sociedad. La mujer fue considerada inferior al varón. Juan Pablo II, reconoce la dificultad para señalar las responsabilidades precisas de este proceso que lamenta sinceramente y afirma: "Que este sentimiento 
profética, en un mundo que atenta contra la dignidad humana de diversas formas, sigue denunciado atropellos contra los más débiles y anunciando que es contraria al plan de Dios cualquier forma de segregación.

La igualdad fundamental entre todos los hombres exige un reconocimiento cada vez mayor. Porque todos ellos, dotados de alma racional y creados a imagen de Dios, tienen la misma naturaleza y el mismo origen. Y porque, redimidos por Cristo, disfrutan de la misma vocación y de idéntico destino.

Es evidente que no todos los hombres son iguales en lo que toca a la capacidad física y a las cualidades intelectuales y morales. Sin embargo, toda forma de discriminación en los derechos fundamentales de la persona, ya sea social o cultural, por motivos de sexo, raza, color, condición social, lengua o religión, debe ser vencida y eliminada por ser contraria al plan divino ${ }^{51}$.

Los Padres Conciliares animan al pueblo de Dios a trabajar para vencer y eliminar cualquier forma de discriminación en los derechos fundamentales de la persona ${ }^{52}$. Los medios a emplear para la toma de conciencia y la defensa de la dignidad humana no se especifican, pero sí se hace evidente la preocupación de nuestros pastores para que la igualdad fundamental del género humano sea reconocida por todos/as.

El magisterio posterior al Concilio ha reafirmado esta verdad sobre el ser humano, hombre y mujer, y su mutua responsabilidad en la realización de la historia. Invitados a la copresencia y colaboración mutuas, ambos, con sus dones, contribuyen al enriquecimiento de la comunión eclesial y al dinamismo del pueblo de Dios. Por eso se insiste en la necesidad de "pasar del reconocimiento teórico de la presencia activa y responsable de la mujer en la Iglesia, a la realización práctica. Y en este preciso sentido debe leerse la presente

se convierta para toda la Iglesia en un compromiso de renovada fidelidad a la inspiración evangélica, que precisamente sobre el tema de la liberación de la mujer de toda forma de abuso y de dominio tiene un mensaje de perenne actualidad, el cual brota de la actitud misma de Cristo". Juan Pablo II, Carta a las mujeres, op. cit., 3 .

51 GS 29

52 "La mujer, allí donde todavía no lo ha logrado, reclama la igualdad de derecho y de hecho con el hombre". GS 9. 
Exhortación, la cual se dirige a los fieles laicos con deliberada y repetida especificación "hombres y mujeres"53. El camino por recorrer es un camino compartido. Hombres y mujeres están llamados conjuntamente a asociarse para colaborar en las tareas que aún quedan por realizar para que se reconozca y resplandezca la igual dignidad de ambos.

También los obispos de Latinoamérica y del Caribe ${ }^{54}$ se fundan en este principio antropológico y advierten sobre los atropellos contra la dignidad de la persona humana, en especial contra los pobres, los indígenas, los afroamericanos y las mujeres. En la realidad que nos ocupa, nuestros obispos acuerdan en que la situación reclama una praxis organizada para que la mujer en igualdad de derechos y obligaciones, esté presente en las realidades temporales para participar con el hombre en la transformación de la sociedad. Señalan la urgencia de un compromiso explícito a favor de la inclusión de las mujeres en la vida pública y eclesial, en tareas de liderazgo y participación activa en diversos ámbitos, que no implique renunciar a la vida familiar y los compromisos que conlleva, para lo cual es necesario un diálogo con los poderes públicos a fin de garantizar leyes que acompañen tal desarrollo.

Los obispos, en Aparecida, continúan y profundizan la reflexión sobre el lugar de las mujeres y la necesidad de transformación de las situaciones que las oprimen para que puedan participar plenamente en la vida eclesial, familiar, cultural, social y económica, creando espacios y estructuras que favorezcan una mayor inclusión. En esta tarea también está comprometida la activa participación de los hombres ${ }^{55}$.

La Biblia nos revela la identidad teológica y cristológica de hombres y mujeres, nos revela que el proyecto de Dios es inclusivo, que nadie puede quedar afuera. La diversidad se convierte en una 
ilimitada fuente de recursos que permiten que la vida social y comunitaria se desarrolle gracias al aporte de todos/as. Se espera así, que hombres y mujeres jueguen un papel activo en el Reino y son llamados a vivir el amor generoso, el servicio, la ternura, la comunión y la entrega recíprocas. De ese modo, será posible crear una sociedad más justa y fraternal a imagen de Dios Trinidad, que desea la vida para todos sus hijos e hijas.

Fundada en las palabras de la Escritura y en las prácticas de Jesús, la reflexión magisterial ha denunciado las injusticias que provoca la discriminación por razones de sexo y ha señalado, con firmeza, la igual dignidad de hombres y mujeres. Es responsabilidad de todos/as promover instancias que permitan reconocer este don para que, tomando conciencia de la igualdad fundamental en la que fueron creados/as, hombres y mujeres, puedan generar relaciones igualitarias, personalizantes y liberadoras.

\section{Reconocimiento y hospitalidad evangélicas. Reconocer y acoger a Jesús que viene}

Los fuertes contrastes en el cruce género-migración, permiten percibir que todavía hay mucho por hacer para forjar relaciones más justas, para reflejar la Comunión de Amor que nos impulsa a realizarla.

En este camino largo, sinuoso, se descubre la necesidad de promover acciones transformativas que broten de la Palabra de Dios y que originen un movimiento desde dentro, no impuesto, que permita ver al otro/otra como un «tú» que, en el encuentro, nos regala una nueva identidad, identidad que se configura allí donde se cruzan las historias, "donde lo extranjero tiene cabida en lo nuestro y nos exige lo que es digno de confianza" ${ }^{56}$. Sin embargo, mientras se vencen las 
resistencias interiores, habrá que articular estrategias comprometidas con las necesidades de quienes viven en situación de movilidad.

Los obispos latinoamericanos invitan a asumir proféticamente una mentalidad y espiritualidad al servicio de la pastoral de los hermanos y hermanas migrantes, tomando conciencia de las demandas de la realidad y promoviendo una formación que permita acompañar estas situaciones tanto en los seminarios y en las casas de formación, como entre el laicado. Como Iglesia sin fronteras, invita a reforzar el diálogo y la cooperación entre las comunidades, para dar una atención humanitaria y pastoral a los que se han movilizado ${ }^{57}$.

En sintonía con estas búsquedas quisiera ofrecer dos claves evangélicas que podrían acompañarlas: el reconocimiento y la hospitalidad.

\section{Reconocimiento}

Al verlo tuvo compasión Lc 10,34

La parábola del buen samaritano (Lc 10,29-37) se inscribe en el transcurso de un diálogo entre Jesús y un maestro de la ley. Las intenciones del legista son puestas en evidencia en la introducción del relato. Queriendo poner a prueba a Jesús, su intervención nos ha regalado de los labios del Maestro, una de sus más bellas enseñanzas.

Para responder a la pregunta, Jesús describe una escena, atravesada por dos personajes relevantes y un extranjero, de quien podía esperarse muy poco. Sin embargo, los sucesos provocan un giro en las expectativas de los oyentes.

Los tres personajes que cruzan al hombre herido lo ven a la vera del camino. De acuerdo a los preceptos de la ley expuestos por el maestro en el diálogo con Jesús, de los dos primeros podría haberse 
esperado que actuaran con caridad hacia el malherido, sin embargo, viéndolo, dieron un rodeo. Solo el samaritano lo reconoce como prójimo, porque al verlo se hizo cargo de su situación, actuando misericordiosamente.

Lo reconoce porque repara en él. Lo advierte, no como una cosa, sino como un alguien, un tú necesitado. Lo advierte y lo considera, contemplándolo como un semejante, con estima y respeto. Al poner su mirada en él, reconociéndolo como prójimo, tuvo compasión y actuó en consecuencia.

Reconocimiento comprometido que entraña la afirmación de la igual dignidad de toda persona. Reconocimiento que subyace a la autovaloración, puesto que debemos nuestra integridad a la aprobación y consideración que recibimos de los demás, a lo largo de nuestras vidas. De hecho, "prestar reconocimiento no es un mero hecho de cortesía, sino una necesidad humana vital"58, cuya satisfacción, (y en su defecto, su carencia) configura la propia biografía. Por tanto, la falta de reconocimiento o el reconocimiento inadecuado, pueden constituir formas de opresión, perjudicando a las personas en la comprensión adecuada de sí mismas, encerrándolas en un modo de ser falso, disminuido, autolimitante.

Este reconocimiento no es solo individual o interpersonal, implica también la afirmación social y política de nuestro valor como seres humanos. Conceder reconocimiento no conlleva solo la visibilización, el ponerse de pie de quienes están siendo infravalorados. Significa, principalmente, transformar las estructuras simbólicas que lo impiden 59 .

En esto Jesús es Maestro. Su osadía al enfrentar con gestos concretos las normativas impuestas por los códigos de honor de su

58 Taylor Charles, Multiculturalism and The politics o Recognition (Princeton: Princenton University Press, 1992), 25. Citado por Nancy Fraser, "¿̇De la redistribución al reconocimiento?", NLR 0 (2000): 130.

Nancy Fraser, op. cit., 132, nota 10. 
tiempo impactan por su fuerte carga simbólica ${ }^{60}$. Sentarse a la mesa con pecadores, dejarse tocar por mujeres consideradas impuras, hablar con extranjeras juzgadas con desprecio, encarnar el amor al prójimo en la persona de un extranjero rechazado, son claros signos de que el reconocimiento no es solo discursivo, sino que ha de operarse con hechos.

Para reconocernos habrá que estar atentos/as al tú próximo, será necesario salir de la indiferencia, de la comodidad. Habrá que tener buenos ojos, una mirada capaz de ir más allá y que a la vez se deje interpelar por la proximidad del que nos reclama. El reconocimiento implica cercanía, nunca rechazo. Para reconocernos tenemos que encontrarnos, dejando de lado la presunción de cualquier jerarquización. En el verdadero encuentro será posible descubrir al «tú»y entrar en comunión, si nos consideramos como pares. En el encuentro podrá darse el reconocimiento recíproco, liberador, que nos descubre siendo con otros/as y gracias a otros/as. Fue un extranjero quien vio al herido y se solidarizó con él.

El reconocimiento del hermano/hermana migrante implicará mirarlo como a uno de tu pueblo, amarlo como a ti mismo (Lev 19,34). Valorar sus orígenes, su cultura, observar cómo interpretan sus propias prácticas sociales, escuchar su palabra, sus demandas, incluirlo/a en la toma de decisiones, valorando sus propias estrategias de transformación, tomando en cuenta las iniciativas que proponen desde su propia realidad y de sus espacios de identificación. Si es uno de tu pueblo, no está al margen de los derechos, ni de los deberes ciudadanos ${ }^{61}$, tiene el derecho y el deber de construir entre todos/ todas una sociedad más justa y una Iglesia que realice y promueva la equidad y la inclusión.

60 Cf. Rafael Aguirre, La mesa compartida (Santander: Sal Terrae, 1994), 35-58.

61 En la actualidad el término ciudadanía no agota su expresión en la elección de los representantes, sino que se define como un espacio de individuos dotados de derechos o que los reclaman. Cf. Isidoro Cheresky, Ciudadanía, sociedad civil y participación política (Buenos Aires: Miño y Dávila, 2006). 


\section{Hospitalidad}

Lo llevó a una posada y cuidó de él

Lc 10,34

Quien ha experimentado la hospitalidad como necesitado o necesitada, aprecia hondamente el sentido profundo que esconde la palabra: saberse reconocido/a, amado/a. Haber recibido un trato más allá del esperado, por el bien recibido, por el bien compartido.

Quien es hospitalario es capaz de reconocer al necesitado/a. Es compasivo/a, se hace cargo, disponiéndose a la acción. El samaritano se acercó, curó sus heridas, lo cargó en su cabalgadura, lo llevó a la posada y cuidó de él. La presencia imprevisible del caminante herido interrumpió sus planes. Pudo reajustar su itinerario, acomodó sus obligaciones y recién después de estar seguro de que estaría atendido, reemprendió la marcha prometiendo volver.

La hospitalidad requiere, al menos, de dos. Nunca es en solitario. A la vez, genera un compromiso que se extiende, pues el posadero también estuvo involucrado.

La hospitalidad supone la kenosis, el abajamiento. Solicita la acogida, el cuidado, el interés que se transforma en compromiso. La hospitalidad nos desafía a descubrir en el extraño un «tú», "un otro/a que me pertenece para recibirlo y valorarlo como regalo de Dios, un don para mí"62. Un don para mí, imagen del amor sin límites de un Dios que se hizo uno de los nuestros, ante la mirada incrédula de quienes no lo recibieron. En el extranjero/a que viene, que llega y se acerca, los cristianos/as somos invitados a contemplar:

el rostro mismo de Cristo, nacido en un pesebre y que, como extranjero, huye a Egipto, asumiendo y compendiando en sí mismo esta fundamental experiencia de su pueblo (cf. Mt 2,13ss). Nacido fuera de su tierra y procedente de fuera de la Patria (cf. Lc 2,4-7), "habitó entre nosotros" (Jn $1,11.14)$ y pasó su vida pública como itinerante, recorriendo "pueblos y 
aldeas" (cf. Lc 13,22; Mt 9,35). Ya resucitado, pero todavía extranjero y desconocido, se apareció en el camino de Emaús a dos de sus discípulos que lo reconocieron solamente al partir el pan (cfr. Lc 24,35). Los cristianos siguen, pues, las huellas de un viandante que no tiene donde reclinar la cabeza (Mt 8,20; Lc 9,58) ${ }^{63}$.

La presencia del hermano, de la hermana inmigrante, constituye para el/la creyente un "verdadero kairos, un tiempo de gracia"64, para vivir la catolicidad, el fortalecimiento de las comunidades, la misión, el diálogo ecuménico e interreligioso, así como la solidaridad ${ }^{65}$.

Con los extranjeros y las extranjeras Jesús irrumpe en nuestras vidas. Nos recuerda que todos somos peregrinos en marcha, sacude nuestra cotidianeidad desacomodando lo rutinario, rompiendo la regularidad y la lógica de la vida diaria, acercando a los que están lejos, desplegando un mundo de acontecimientos solo posibles si nos abrimos a la novedad de quien viene a recibirnos. Por eso la hospitalidad es un gesto en el que hacemos presente al Dios que nos espera en su casa. Te recibo hermano, te recibo hermana, escucho tu voz y te abro la puerta, entonces comeremos juntos. La puerta abierta, la mesa tendida, signos de comunión eucarística que anticipan la promesa del encuentro definitivo para los que peregrinamos en esta tierra. Hospitalidad sin fronteras, si todos son bienvenidos. Por esto somos invitados como Iglesia a forjar comunidades donde nadie pueda sentirse extranjero, porque "en la Iglesia nadie es extranjero"66.

Las historias se cruzan. Las voces de quienes migran forzadamente, la solidaridad del extranjero que reconoce prójimo al caminante herido, la presencia de quienes llegan de lejos a realizar sus proyectos junto a nosotros/as, la decisión de quienes se lanzan más allá de la frontera tras sus sueños.

63 Pontificio Consejo para la Pastoral de los Emigrantes e Itinerante, op. cit., 15.

64 Conferencia Episcopal Española, La Iglesia en España y los inmigrantes (Madrid: Edice, 2007), 17-21.

65 Cf. Ibíd., capítulo 3.

66 Mensaje de Juan Pablo II en la Jornada Mundial del Emigrante de 1996. "En la Iglesia nadie es extranjero, y la Iglesia no es extranjera para ningún hombre y en ningún lugar. Como sacramento de unidad y, por tanto, como signo y fuerza de agregación de todo el género humano, la Iglesia es el lugar donde también los emigrantes indocumentados son reconocidos y acogidos como hermanos". Disponible en: www.vatican.va/holy_father/john_paul_ii/messages/migration/index_sp.htm 
Contemplando sus rostros decimos: ustedes son también un sacramento, una imagen del rostro siempre vivo de Jesús. Ojalá que celebremos el encuentro haciendo fiesta, en comunidades que ofrezcan a unos y a otras "una ciudadanía universal en la que no haya distinción de personas" ${ }^{\prime 67}$.

\section{Bibliografía}

Adital, SJRM denunciaaumento de tráfico de pessoas na fronteira entre Haiti e RD www.adital.com.br/hotsite_trafico/noticia. asp?lang $=\mathrm{PT} \& \operatorname{cod}=51485$ (consultada en noviembre 10, 2010).

Adital, "Alertas sobre explotación estimulan creación de red contra la trata de personas" www.adital.com.br /site/noticia. asp? boletim $=1 \&$ lang $=\mathrm{ES} \& \operatorname{cod}=51251$ (consultada en septiembre 27, 2010).

Aguirre, Rafael. La mesa compartida. Santander: Sal Terrae, 1994.

Anzaldúa, Gloria. This Bridge Called My Back. Watertown, M.A.: Persephone Press, 1981.

Bargalló, Mons. Fernando. Alocución apertura II Foro Regional de Género, 8 de octubre de 2010. www.caritaslac.org/noticia. aspx?id=670. (consultada en septiembre 2, 2010).

Bingemer, María Clara. Um rostro para Deus? Sao Paulo: Paulus, 2005.

Carta a los Obispos de la Iglesia católica sobre la colaboración del hombre y la mujer en la Iglesia y el mundo. www.vatican.va/ roman_curia/congregations/cfaith/documents/rc_con_cfaith_doc_20040731_collaboration_sp.html (consultada en septiembre 2, 2010). 
Cheresky, Isidoro. Ciudadanía, sociedad civil y participación política. Buenos Aires: Miño y Dávila, 2006.

Chumbita, Hugo. Ultima frontera. Vairoleto: Vida y leyenda de un bandolero. Buenos Aires: Planeta, 1999.

Conferencia Episcopal Española. La Iglesia en España y los inmigrantes. Madrid: Edice, 2007.

Di Nicola, Giulia. Reciprocidad hombre-mujer. Madrid: Narcea 1991.

Eckholt, Margit. "La gracia del invitado. Hacia una hermenéutica teológica del camino de Emaús-Hitos de una dogmática fundamental intercultural". Teología 84 (2004): 9-25.

Eriksson, Linda. "Género y remesas: migración colombiana del AMCO hacia España", OIM y el Instituto Internacional de Investigaciones y Capacitación de las Naciones Unidas para la Promoción de la Mujer, 2005. Disponible en: http://tukuymigra.com/images/normativa/COL_EST_OIM-DANE_4. pdf (consultada en octubre 5, 2010).

Escrivá, Ángeles. “¿Empleadas de por vida? Peruanas en el servicio doméstico de Barcelona". Papers 60 (2000): 327-342.

"Fabiana Tuñez: en el último año han desaparecido 627 mujeres y niñas". Ahora es nuestra ciudad. http://ahoraesnuestralaciudad2009. blogspot.com/2010/03/fabiana-tunez-en-el-ultimo-ano-han. html (consultada en marzo 10, 2011).

Fraser, Nancy. "¿De la redistribución al reconocimiento?" NLR 0 (2000): 126-155.

Goñalons, Pilar; Flecha, Ramón; Santacruz, Iñaki y Gómez, Carlos. "Las aportaciones y los retos de la perspectiva transnacional: una lectura de género". En el Congreso Nuevos retos del transnacionalismo en el estudio de las migraciones (Barcelona: febrero 2008): 12-14. http://docsgedime.wordpress. com (consultada en septiembre 2, 2010). 
Gregorio Gil, Carmen. "Mujeres inmigrantes: colonizando sus cuerpos mediante fronteras procreativas, étnico culturales, sexuales y reproductivas". Viento Sur 104 (2009): 42-54.

. Migración femenina: su impacto en las relaciones de género. Madrid: Narcea, 1998.

- "Debates feministas en el análisis de la inmigración no comunitaria en el estado español. Reflexiones desde la etnografía y la antropología social". Relaciones Internacionales 14 (2010) 93-115,101. http://relacionesinternacionales.info/ ojs/index.php?

journal $=$ Relaciones_Internacionales $\&$ page $=$ article\&op $=$ view $\&$ pat $\mathrm{h} \% 5 \mathrm{~B} \% 5 \mathrm{D}=217 \&$ path\%5B\%5D = 196 (consultada en septiembre 2,2010 ).

Informe 2010 sobre la trata de personas www.america.gov/st/democracyhr-spanish/2010/June /20100614112332fjnoeled0. 3156855.html (consultada en febrero 8, 2011).

Instituto de las Naciones Unidas de Investigación para el Desarrollo Social (UNRISD) versión informática: www.unrisd.org/ unrisd/website/document.nsf/\%28httpPublications\%29/54 B9DD585F891F6DC12571630047FFF0?OpenDocument (consultada en febrero 10, 2011).

Institute of Develoment Satudies 2005, Informe general BRIDGE, versión informática: www.pazysolidaridad.ccoo.es/abrefichero.asp? Idfichero $=24$ (consultada en diciembre 20, 2010).

Johnson, Elizabeth. La que es. Barcelona: Herder, 2002.

Jones, Serene. Feminist Theory and Christian Theology. Minneapolis: Fortress Press, 2000.

Juan Pablo II, Carta a las mujeres. www.vatican.va/holy_father/ john_paul_ii/letters/documents/hf_jp-ii_let_29061995_women_sp.html (consultada en septiembre 2, 2010). 
. Mensaje de Juan Pablo II en la Jornada Mundial del Emigrante de 1996, www.vatican.va/holy_father/john_paul_ii/ messages/migration/index_sp.htm (consultada en septiembre 2, 2010).

. Mensaje de Juan Pablo II en la Jornada Mundial del Emigrante de 1995, www.vatican.va/holy_father/john_paul_ii/ messages/migration/index_sp.htm (consultada en septiembre 2, 2010).

La Gente, "Ventas de mujeres migrantes, nuevo negocio de narcos en México," www.radiolaprimerisima. com/noticias/inmigrantes/91314. (consultada en febrero 8, 2011).

Lamas, Marta. "La antropología feminista y la categoría de género". En Nueva antropología. Estudios sobre la mujer: problemas teóricos, editado por Ludka de Gortari. Iztapalapa: CONACYTI/UAM, 1986.

Martínez Pizarro, Jorge. El mapa migratorio de América Latina y el Caribe, las mujeres y el género. Santiago: CEPAL,2003. www.oas.org/atip/Migration/CEPAL\%20Study\%20on\%20 Migration.pdf (consultada en septiembre 27, 2010).

Orosco, Amaia. Cadenas globales de cuidado. Santo Domingo: INSTRAW, 2007.

Pablo VI, "Discurso contra las injustas desigualdades entre ricos y pobres", Ecclesia 28 (1968)

Parella Rubio, Sonia. Mujer, inmigrante y trabajadora: la triple discriminación. Barcelona: Anthropos, 2003.

Pontificio Consejo para la Pastoral de los Emigrantes. Erga migrantes caritas Christi, www.vatican.va/roman_curia/ pontifical_councils/migrants/documents/rc_pc_migrants_ doc_20040514_erga-migrantes-caritas-christi_sp.html (consultada en septiembre 27, 2010). 
Sassen, Saskia. Los espectros de la globalización. Buenos Aires: Fondo de Cultura Económica, 2003.

Scott, Joan. "El género: una categoría útil para el análisis histórico". En Sexualidad, género y roles sexuales, editado por M. Navarro y C.R. Stimpson, 37-75. México: Fondo de Cultura Económica, 1999.

SEMLAC, "Colombia: feminización de la inmigración en la zona cafetera," www.redsemlac.net/web/index.php? option $=$ com_content $\&$ view $=$ article $\&$ id $=219$ : colombia - feminizacion-de-la-migracion-en-la-zonacafetera\&catid $=47$ : :genero\&Itemid =66 (consultada en febrero 25, 2010).

Sicre, José L. El Pentateuco. Introducción y textos selectos. Buenos Aires: San Benito, 2004.

Sierra, Gustavo. "Los jinetes de La Bestia", Clarín, abril 3, 2011, Sección Zona.

Stoller, R. y Herdt, G. "El desarrollo de la masculinidad: una contribución transcultural". Revista de la Asociación Escuela Argentina de Psicoterapia para Graduados 18 (1992): 189-216.

Tubert, Sivia. Del sexo al género. Los equívocos de un concepto. Madrid: Cátedra, 2003.

UNEP, "La mujer y la desertificación", www.unep.org/PDF/Women/ Spanish/ChapterFour.pdf (consultada en septiembre 15, 2010).

Varela, Graciela. "Mujeres partidas: análisis discursivo de historias de migración". En Migraciones internacionales en la década el 90 en argentina, editado por Silvia Chejter. Buenos Aires: CECYM, 2005. 